\title{
DO UNEMPLOYMENT INSURANCE RECIPIENTS ACTIVELY SEEK WORK? RANDOMIZED TRIALS IN FOUR U.S. STATES
}

\author{
Orley Ashenfelter \\ David Ashmore \\ Olivier Deschênes
}

Working Paper 6982

http://www.nber.org/papers/w6982

\author{
NATIONAL BUREAU OF ECONOMIC RESEARCH \\ 1050 Massachusetts Avenue \\ Cambridge, MA 02138 \\ February 1999
}

This research was financed through a contract between the U.S. Department of Labor and Princeton Economic Research, Inc. (PERI). We are indebted to many people for their assistance with this project, but we owe an especial debt to Dr. Basheer Ahmed, President of PERI. Olivier Deschênes gratefully acknowledges financial support from the Social Sciences and Humanities Research Council of Canada. The views expressed in this paper are those of the authors and do not reflect those of the National Bureau of Economic Research.

- 1999 by Orley Ashenfelter, David Ashmore, and Olivier Deschênes. All rights reserved. Short sections of text, not to exceed two paragraphs, may be quoted without explicit permission provided that full credit, including ${ }^{\circledR}$ notice, is given to the source. 
Do Unemployment Insurance Recipients Actively Seek Work?

Randomized Trials in Four U.S. States

Orley Ashenfelter, David Ashmore, and Olivier Deschênes

NBER Working Paper No. 6982

February 1999

JEL No. C93, J65

\section{ABSTRACT}

In the last two decades, U.S. policies have moved from the use of incentives to the use of sanctions to promote work effort in social programs. Surprisingly, except for anecdotes, there is very little systematic evidence of the extent to which sanctions applied to the abusive use of social entitlements result in greater work effort. In this paper we report the results of randomized trials designed to measure whether stricter enforcement and verification of work search behavior alone decreases unemployment (UI) claims and benefits. These experiments were designed to explicitly test claims based on non-experimental data, that a prime cause of overpayment is the failure of claimants to actively seek work. Our results provide no support for the view that the failure to actively seek work has been a cause of overpayment in the UI system.

Orley Ashenfelter

Industrial Relations Section

Firestone Library

Princeton University

Princeton, NJ 08544

and NBER

Olivier Deschênes

Department of Economics

Princeton University

Princeton, NJ 08544
David Ashmore

Ashenfelter \& Ashmore

169 Nassau Street

Princeton, NJ 08542 


\section{Introduction}

In the last two decades U.S. policies have moved from the use of incentives to the use of sanctions to promote work effort in social programs. This shift in orientation in public policies has been documented by Jencks (1992), who, like Murray (1984), argues that it has been based, in part, on the perception that these programs are riddled with abuse. Surprisingly, except for anecdotes, there is very little systematic evidence of the extent to which sanctions applied to abusive use of social entitlements result in greater work effort.

In this paper we report the results of the only field test of which we are aware that uses randomized trials to measure whether stricter enforcement and verification of work search behavior alone decreases unemployment claims and benefits paid in the U.S. unemployment insurance (UI) program. These experiments, which we implemented in four sites in Connecticut, Massachusetts, Virginia, and Tennessee, were designed to explicitly test claims based on nonexperimental data, summarized in Burgess and Kingston (1987), ${ }^{1}$ that a prime cause of overpayments is the failure of claimants to actively seek work.

Our results provide no support for the view that the failure to actively search for work has been a cause of overpayments in the UI system. These results provide a much needed complement to the results of other UI system experiments reported by Meyer (1995), who first brought these unique field experiments to broad attention. The treatments in the experiments Meyer (1995) surveys, which he reports were cost effective, incorporated elements of both work search verification and a system designed to teach workers how better to search for jobs. The experiment reported here incorporated only the element of work search verification, and we find that the treatments provided no benefits. Taken together, the results of both sets of experiments imply that providing workers with subsidized job search assistance may be a relatively inexpensive way to provide cost effective, but small, benefits to both workers and society.

In the remainder of the paper we first describe our experimental design, the nature of the experimental treatment, and our data collection procedures. Since randomization is so important

\footnotetext{
1 See also Kingston, Burgess, and St. Louis (1986) and Wolf and Greenberg (1986)
} 
for our estimation procedure, and since there is some evidence that several field experiments have not been properly randomized, we next report tests of the effectiveness of our simple randomization technique. Finally, we report the effect of the experimental treatment on claimant qualification rates, benefit payments, and claim durations.

\section{Research Design, Experimental Treatment, and Data Collection Procedures}

\section{A. The Treatments}

In each state, the treatment consisted of a number of new steps in the processing of initial claims for unemployment insurance prior to the issuance of the first check ${ }^{2}$. The new steps were implemented via supplemental questionnaires and reviews, as additions to or modifications to the pre-existing procedures. Claimants in the control group were processed via the preexisting procedures. As a result, the number of new procedures in the treatment varied across states, reflecting the differences between the pre-existing procedures in these states. A diagram representing the application processing procedures in the treatment and control group is contained in Figure 1, and provides a helpful way to describe the experiments.

As Figure 1 indicates, there were, in fact, two treatment groups:

Overall treatment group (Group 1). The overall treatment group was treated differently from the control group in two ways. First, as Figure 1 indicates, some processes that were provided to the control group at the second visit to the $\mathrm{Ul}$ office were instead provided at the first visit. The main part of the process that was provided earlier to the treatment group was the administration of the Benefit Rights Interview (BRI), wherein the claimant's responsibility to actively search for work as well as other responsibilities are explained.

Second, some processes were provided to all members of the overall treatment group that were not provided to the control group at all. All the members of the overall treatment group (Group 1) received an expanded initial eligibility questionnaire designed to explore whether the

\footnotetext{
${ }^{2}$ This is an important difference from the design of other Work Search Experiments where the treatment was in general provided after issuance of the first check or later.
} 
claimant meets the able and available requirement ${ }^{3}$ or has other relevant income. In addition, at the initial visit, the active search for work requirement was emphasized to the claimant, and the claimant received a series of forms (the work search plan, the work search instruction sheet and the work search report form). The claimant was instructed to begin an immediate active work search and was informed that such search is subject to verification. In addition, at the initial visit, the treatment group received and completed a work history form, listing all relevant base-period employment and wages. This form was used to make an extensive review of the accuracy of the monetary determination at the time of the second visit to the UI office.

Work Search Verification Treatment (Group 3). For part of the control group (Group 3) an additional aspect of the treatment involved an actual verification that the claimant undertook the job search. To do this, at the second visit to the $U$ l office the completed work search report form was reviewed to evaluate the appropriateness of the claimant's work search. In addition, job search contacts of a random sample of the treatment group were verified by telephone before the first check was issued.

Table A-1 in the appendix summarizes the major differences across states between the experimental procedures and the existing state's procedures. Applicants in the treatment groups who failed to meet these new requirements were disqualified for benefits, either temporarily or permanently. As a consequence, compliance with the treatment is not an issue here as claimants must go through the procedures (experimental or control) in order to receive their benefits. In order to eliminate the possibility of Hawthorne effects, which can arise when individuals change their behavior because they know it is under study, the claimants were never informed that they were taking part in a randomized experiment.

\section{B. Randomization}

The population group considered for assignment to the treatment group consists of enrolling applicants filing initial, in-person, intrastate $U I$ benefit claims ${ }^{4}$ during the

\footnotetext{
${ }^{3}$ This means that the claimant must be able, ready and willing to accept full time work with reasonable efforts.

4 Individuals filing transitional, continuing or interstate claims were excluded.
} 
experimental period, which varied slightly across states ${ }^{5}$. Randomization into the treatment and control groups was based on the $7^{\text {th }}$ digit of the applicant's Social Security number. It is well known that the last four digits of Social Security numbers are not assigned deterministically, so this method provides a unique, but random, identification for each applicant at a trivial cost. Nevertheless, in view of reports that some field experiments (see Meyer (1995)) have not been properly randomized, we report tests of the effectiveness of this method below. The period of enrollment into treatment and control groups ran from December of 1984 to April of 1985.

\section{Data Sources and Collection}

The data used in the analysis come from two sources. Data on the outcome of claims applications at the initial visit to the UI office (in particular qualification, disqualification, amount of first check) and on claimants characteristics were collected by the UI office personnel. The local offices collected information on all valid applications during the study period. The experimental effects associated with these short-run outcomes are estimated using this data set.

Data on longer run outcomes of the unemployment spells, such as total benefits received and claim duration, were obtained from each state's central data processing department. These longer run outcomes were in general measured one month after the end of the study period, though that period of time varied in each state. For that reason, we will refer to the claim duration variable as the observed claim duration since our measure is not always a measure of the length of a completed claim. The analysis of duration variables and the measurement of treatment effects in the context of random assignment are not as straightforward as is sometimes the case.

For example, using data from the National Supported Work (NSW) Demonstration, Ham and Lalonde (1996) showed that samples of individuals in new spells of employment after the treatment (training program) has been randomly assigned to unemployed workers were not random subsets of the experimental sample. In our context, this should not be a serious problem because individuals in the control and treatment group remain in the same state (that is, unemployed) while the treatment is provided to the individuals in the treatment group.

\footnotetext{
${ }^{5}$ See the appendix for more information on the experimental periods.
} 
Nonetheless there is a serious problem with our long-run outcomes samples in two of the four states because of the data collection system used. In both Tennessee and Virginia, the longer run outcomes were recorded only for claimants whose claim was still active at the date of meast ement, so that claim duration is right-censored ${ }^{6}$. If the treatment has any sort of impact in reducing the duration of unemployment, then the probability of observing a censored unemployment spell will differ between the treatment and control groups, which should not be the case under random assignment. For these two states, therefore, it is possible that the samples on longer run outcomes are not random subsets of the experimental sample. For this reason, we perform separate statistical tests of random assignment on the basis of the claimant's demographic characteristics on data coming from both short-run and long run outcomes samples. In addition, we provide some analyses that are restricted to the data for the two states where we are certain random assignment was not compromised.

\section{The Effectiveness of the Randomization}

Tables $1 \mathrm{a}$ and $1 \mathrm{~b}$ present descriptive statistics for each of the study groups. Table $1 \mathrm{a}$ is based of the full sample of demographics and short-run claim outcomes obtained from each participating local UI office in each state, while Table $1 \mathrm{~b}$ is based on the smaller sample for which we have longer run outcome measures. Corresponding to the discussion of the treatments presented above we have presented data on four separate groups. In the groups labeled "All Sample" we have provided data for the "Control" group in column (2), and data for the overall "Treatment" group in column (1). Since we selected whether a claimant was in the treatment or control group randomly, about one-half of the total sample falls in each group. Under the columns labeled "WSV" we have placed data on the groups that can be used to test for whether the work search verification treatment had an impact separate from the remainder of the treatment process. The "Treatment" group in column (3) was subject to work search verification, while the "Control" group in column (4) was subject only to the other parts of the treatment

\footnotetext{
- In Virginia, about $5 \%$ of the observations were not right-censored.
} 
process. The number of observations in column (1) is therefore the sum of the number of observations in columns (3) and (4).

These tables describe the socioeconomic characteristics and mean week benefit amount (WBA). As is apparent from the tables, the means of these variables are remarkably similar across group within a state. To study the effectiveness of our randomization method we tested the hypothesis of equality of means (or proportions) for all the variables in the relevant treatment and control groups combinations, that is (1) vs. (2), (3) vs. (2) and (4) vs. (2). For the full sample of demographics and short-run claim outcomes in Table 1a, the results are consistent with randomization ${ }^{7}$ in almost all cases. The exceptions are a significantly different age variable in the treatment and control groups in Virginia, and significant differences in the race proportions and the gender proportions in the comparison of columns (3) versus (4) in Tennessee and Virginia, respectively. Thus, in 57 contrasts there are three contrasts that are statistically significant at the .05 level, which is almost precisely what would be expected (that is, $.05(57)=2.85$ ) if assignment were random. In all cases, moreover, the differences, even when statistically significant, are very small.

In another attempt to verify the effectiveness of the random assignment, we tested the null hypothesis of equality of the distribution function of the demographic variables using a Kolmogorov-Smirnov test (see DeGroot 1975 p.558). In all cases we were unable to reject the hypothesis of equality of the distributions.

Finally, we performed the same tests reported above for the sample of long-run claim outcomes in Table 1b. In general these results are also consistent with randomization. In fact, the patterns of rejection of equality of means are almost the same as for the full sample of demographics and short-run claim outcomes.

These statistical tests, based on the observable characteristics of the treatment and control group, suggest strongly that the treatment and control groups were indeed drawn from the same population. We will therefore estimate experimental effects using standard analysis-ofvariance methods. In addition, we use regression methods to estimate treatment effects in order

\footnotetext{
${ }^{7}$ We use a two-sided t-test for equality of means at the $5 \%$ level.
} 
to capture any gains in efficiency that may exist. A comparison of the difference between the results before and after adjustment for regression provides another test for the presence of randomization. If the randomization was effective the two sets of estimates should not differ apart from that which may be attributable to sampling error. Nonetheless, as discussed earlier, for two states (TN and VA) data on long-run claim outcomes was collected on a potentially non-random subset of the claim outcomes, and so we report some results that eliminate these data from the results.

\section{Estimated Effects of the Treatments}

Table 2 displays simple summary statistics on several measures of program outcomes for the treatment and control groups. These measures of location are based on two different samples. The "Qualification Rate" panel is based on the same samples that underlies Table 1a, that is the full sample of demographic variables and short run claim outcomes coming from each local UI office. It provides details on the extent to which the treatment resulted in applicants being denied claims at various points in the process. The "Benefit Payments" and "Claim Duration" panels are based on the same sample that underlies Table $1 \mathrm{~b}$, that is the sample of long-run claim outcomes variables that was provided by the state's central data processing departments. In general, the long run outcome samples are smaller than the samples containing demographic variables only.

Tables 3 to 6 display the various responses of the claimants to the experimental procedures. For each program variable related to the experimental procedures we present four measures of the experimental effects. For each variable of interest, we present differences in means (or quantile) ${ }^{8}$ and estimated regression coefficients that control for additional characteristics. Under random assignment the estimates of the experimental effects obtained by regression methods should not differ from the estimates obtained by comparison of means (apart from sampling error), but could be more precise. Since in our applications most of the variation in the dependant variable is unexplained (the regressions have $\mathrm{R}^{2}$ less than .05 ), the improvement in the precision of the estimates is negligible. It should be noted that it is not possible to isolate the specific 
impact of the three components of the treatment (eligibility, monetary determination and work search). We can achieve partial identification by looking at contrasts that contain a unique component of the treatment.

The first column is the overall treatment effect, the difference between the "All Sample" treatment and control outcomes. This treatment effect is the combined result of the three elements of the experimental procedures. The remaining columns measure the part of the overall treatment effect associated with work search verification. The second column presents the difference in means between the claimants in the treatment group whose job contacts were not verified (4) and the claimants in the control group (2), who by definition were not given the work search verification part of the treatment. This difference measures the result of receiving the eligibility and monetary determination elements of the experimental procedures plus the effect of stressing the rules of work search as a requirement for claiming UI benefits. The third column presents the difference in means between the claimants in the treatment group whose job contacts were actually verified (3) and the claimants in the treatment group who did not have their job contacts verified (4). Since claimants in groups (3) and (4) receive the same treatment, except for the actual work search verification, this difference measures the specific impact on claim outcomes of actually verifying the job contacts of claimants. The fourth column presents the difference in means between the claimants in the treatment group whose job contacts were actually verified (3) and the claimants in the control group (2), who by definition were not given the work search part of the treatment. This measures the combined impact of informing the claimant and actually verifying the appropriateness of the claimant's work search, in addition to the eligibility and monetary determination parts of the experimental procedures.

As this discussion illustrates, it is possible to uniquely identify only one component of the experimental treatment. The difference in responses between experimental groups (3) and (4) yields an estimate of the effect on outcomes of actually verifying the appropriateness of the work search behavior of the claimants. Since individuals in the treatment group either get their job search contacts verified (group (3)) or not (group (4)), we can always write the mean of an

\footnotetext{
${ }^{8}$ It should be noted, as we will discuss below, that difference in quantiles are not in general unbiased estimates of the
} 
outcome in the treatment group (1) as $X_{1}=p X_{3}+(1-p) X_{4}$, where $p$ is the fraction of the treatment group which gets job search contacts verified. Then the overall treatment effect ${ }^{9}$, that is the mean outcome in the treatment group minus the mean outcome in the control group $\left(X_{1}-X_{2}\right)$, can be written as $\left(X_{4}-X_{2}\right)+p\left(X_{3}-X_{4}\right)$. The second part of the mean difference $p\left(X_{3}-X_{4}\right)$ reflects the importance in the overall treatment of actually verifying the appropriateness of the work search behavior of the claimants. The first part of the mean difference $\left(X_{4}-X_{2}\right)$ reflects the importance in the overall treatment effect of the combination of all other parts of the experimental procedures, without the verification of the job search contacts. This simple formula permits partial identification of the specific impacts of the 3 elements of the experimental procedures.

The object of interest in the evaluation of experiments is the effect of the treatment on the distribution of outcome variables. Unless we observe the same individuals in the treated and untreated states (which is not the case in most instances) we cannot observe the experimental effect for any particular individual. One implication of randomization is that the outcome distribution for individuals in the treatment group summarizes the outcome distribution that individuals in the treatment group would have had if they had been in the control group, that is, if they had not received the treatment. As a result, the difference in means of outcomes in the treatment and control group is the mean of the (unobserved) distribution of experimental impacts. Without further assumptions, the same conclusion is not true for other parts of the experimental effects distribution. For example, the difference in the median outcomes in the treatment and control group is not in general equal to the median impact of the experiment. A discussion of this issue is presented in Heckman (1992) and Heckman, Smith and Clements (1997). Under the assumption of "common experimental effect", where the experimental impact is assumed to be the same for all the participants, the difference in the medians (or any other quantile) recovers the median impact. This assumption is unlikely to hold in our experiment ${ }^{10}$. For example, there is no reason to believe that the work search component of the experimental procedures should reduce the length of the unemployment spell of all the claimants in the treatment group by the same

quantiles of the experimental effects distribution as it is the case for means.

This decomposition is only valid when we look at the difference in means.

${ }^{10}$ Heckman, Smith and Clements (1997) propose some methods to test the "common experimental effect" model. 
amount. As a consequence, when looking at the tables, the reader should not interpret the differences in quantiles as unbiased estimates of the quantiles of the impact distribution. ${ }^{11}$ Nevertheless, the difference between the quantiles in the treatment and control distributions does provide an appropriate estimate of the effect of the treatment on the distribution of the outcome variables.

\section{A. Impact on the Qualification Rate}

The impact of the experimental procedures on the qualification rate mainly reflects the effectiveness of the eligibility component of the experiment, which focussed on detecting ineligible claimants via an extended questionnaire. Thus, if current procedures are ineffective in detecting non-eligible claimants, the most immediate effect of the eligibility review component of the experimental procedures should be to increase disqualifications and reduce those qualified for benefits in the first week of eligibility in the treatment group. We analyze differences in the treatment and control groups for the following outcomes: the fraction of claimants qualifying for benefits in the first week, the fraction of claimants disqualified permanently (for the most part based on the reason for separation or the failure to have significant earlier earnings), the fraction of claimants disqualified temporarily (which mainly reflects "able and available" issues, or transitory income or work search issues), and the fraction of "no-shows" (those claimants not formally disqualified who did not show up at their scheduled second visit to the UI office). The analysis of the "no-shows" variable allows us to measure the relative importance of endogenous stratification (see Hausman and Wise (1985)) in our experimental design.

The top panel of Table 2 presents the sample proportions of the qualification-related variables for all the study groups. The fraction of claimants qualifying for benefits in the first week of eligibility is quite similar among Connecticut, Massachusetts, and Tennessee, but somewhat higher in Virginia. There is much more variation across states in the three other short run claim outcome variables. In some states, almost all of the disqualifications are permanent (CT, MA, TN), while in VA almost all disqualifications are temporary. The fraction of "no-shows" is in general small, except in MA, where it is around $15 \%$.

\footnotetext{
"As in the example in Heckman, Smith, and Clements (1997), the nonparametric bounds procedure they suggest
} 
The top panel of Table 3 displays the program treatment effects on the qualification rate. Any effect of the experimental procedures on the qualification rate should mainly reflect the eligibility review component of the experimental procedures. The bottom panel presents the same differences in proportions, but from a linear probability model that controls for various factors (which are listed in the stub of the table). It is clear from Table 3 that the experimental procedures had very moderate effects on the qualification rate outcomes. In each state (except in CT), the overall experimental effects (column 1) are small in magnitude and not significantly different from 0 . The experimental effect on the qualification rate in the first week is of the expected negative sign in all states, except in VA, where it is positive. The effect on the qualification rate in the first week is only significant in CT where applicants in the treatment were $8 \%$ less likely to qualify for benefits during the first week of eligibility. Using the decomposition of means formula presented above, we can conclude that in CT most of the overall treatment effect on qualification in the first week is explained by the combination of the three elements of the experimental procedures, and not by the actual verification of work search requirements. This suggests that the eligibility questionnaire was effective in detecting ineligible claimants.

The experimental effects on temporary and permanent disqualifications provide further information on the effect of the treatment on benefit receipt. The effect of the experiment on disqualifications is of the expected positive sign in all states, except again in VA, where it is negative. These results indicate that the experimental procedures tend to increase disqualifications, but by a very small amount that is not statistically significant. The treatment effects related to the "no-show" variable are in all cases small in magnitude ( $2 \%$ or less) and in most cases not significant. This indicates that the probability of claimants withdrawing themselves from the experiment is not correlated with the assignment in the treatment and control group. Hence the potential problem of endogenous stratification can be left aside in the following discussion. Regression adjusted results are presented in the bottom panel of Table 3. The results are almost identical to those contained in the top panel.

B. Impact on Benefits Payments

provides very little information on the size of treatment effects in our data. 
The impact of the experimental procedures on the benefit payments reflects the interaction between the effectiveness of the review of monetary determination and the work search components of the experimental procedures. The former aims at identifying overpayments due to incorrect monetary determination while the later aims at reducing the unemployment claim length by increasing the cost of inappropriate job search. We analyze differences in the treatment and control groups for the following outcomes: total benefits received (up until the point of measurement of the long-run outcomes), average weekly benefits, and the

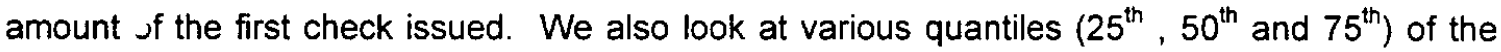
total benefits variable ${ }^{12}$. Since some claims will still be active at the date of measurement, we do not consider the mean of the total benefits variable to be an ideal estimate of the mean of total benefits received for a completed claim. It is likely to underestimate total benefits. Total benefits and average weekly benefits, both of which are determined by total claim duration and by the weekly benefit amount (WBA), should be affected by the two components of the experimental procedures mentioned above. The amount of the first check issued should only be affected by the review of monetary determination. Thus the most immediate effect of the review of monetary determination and work search components of the experimental procedures should be to decrease total benefits, average weekly benefits, and the first check issued in the treatment group.

Table 4 presents estimates of the experimental effects on benefit payments. None of the mean or median treatment effects is statistically significant. Moreover, in TN and VA, the effects are opposite of the sign expected, as claimants in the treatment group received on average higher total benefits for the observed duration of the claim. The same observation applies to the average weekly benefits variable, though a significant negative treatment effect of $12 \$$ a week is observed in CT. Since the amount of the first check issued is independent of the observed claim duration, any experimental effect on that variable is a result of the effectiveness of the review of the monetary determination component of the experimental procedures. The effect on the first check issued is only significant in CT where applicants in the treatment group received 8 dollars

\footnotetext{
${ }^{12}$ We use these various quantiles in addition to the means since they are less influenced by extreme values.
} 
less than their counterparts in the control group. For the rest of the participating states, the experimental effects are insignificant and of a sign opposite to that expected, i.e. claimants in the treatment group received larger amounts in their first check. There is no clear pattern that emerges when we look at the differences in various quantiles of the total benefits received distribution. The differences between the treatment and control groups tend to be bigger in the tails of the distribution ( $25^{\text {th }}$ and $75^{\text {th }}$ quantiles) than at the median ${ }^{13}$. Regression adjusted results are presented in the bottom panel of Table 4. The results are quantitatively the same as in the top panel.

In sum, claimants in the treatment group do not appear to receive substantially smaller benefit payments than claimants in the control group. The review of the monetary determination was also unsuccessful in identifying overpayments in the treatment group, as the treatment effects on the first check issued variable are positive (instead of the expected negative sign) but non-significant. The exception is CT where the first check issued is reduced by $8 \$$ on average in the treatment group. It appears that for that state, the review of monetary determination reached its objectives.

\section{Impact on Claim Duration}

The direct effect of the work search component of the experimental procedures is to provide claimants an incentive to search actively for work. Thus, the most immediate effect of this component of the experimental procedures should be to reduce the length of unemployment claims. We analyze differences in means (and quantiles) in the treatment and control groups for the observed claim duration. In addition, we can decompose the difference in means in the following way:

$X_{1}-X_{0}=\left[c_{1} X_{1 c}+\left(1-c_{1}\right) X_{1 n c}\right]-\left[c_{0} X_{0 c}+\left(1-c_{0}\right) X_{0 n c}\right]$

Where $X_{1}$ and $X_{0}$ are the average observed claim duration in the treatment and control groups respectively, $c_{1}$ and $c_{0}$ are the probabilities of censoring in the treatment and control groups, $X_{1 c}$

\footnotetext{
${ }^{13}$ Standard errors of the differences in quantiles were obtained by the bootstrap method, with 5000 replications. For more
} 
and $X_{O c}$ are the average claim duration of censored spells in the treatment and control groups and $\mathrm{X}_{1 \mathrm{nc}}$ and $\mathrm{X}_{\mathrm{Onc}}$ are the average claim duration of non-censored spells in the treatment and control groups. Then using a decomposition of the above formula, we can write:

$X_{1}-X_{0}=\left(c_{1}-c_{0}\right) X_{1 c}+\left[\left(1-c_{1}\right)-\left(1-c_{0}\right)\right] X_{1 n c}+\left(X_{1 c}-X_{0 c}\right) c_{0}+\left[X_{1 n c}-X_{0 n d}\right]\left(1-c_{0}\right)$

The first two terms represent the difference in mean duration due to differences in the probabilities of censoring (and non-censoring) across the treatment and control groups, while the last two terms represent the difference in means due to the difference in average censored and non-censored claim duration in the treatment and control groups. We present each of these four components as a fraction of the overall mean difference. Since the observations on long-run outcomes are all censored in TN and VA, we cannot perform this decomposition for these two states.

The bottom panel of Table 2 presents the mean and median of the observed claim durations. Variation across states reflects the difference in the impacts of the treatment across states, but also the fact that the date of measurement after the experimental period was not uniform across states ${ }^{14}$. For most states, the average observed claim duration ranges from 4 to 6 weeks, while in VA, the average is substantially higher, 20 weeks. This is due to the fact that data on the long-run outcomes (including claim duration) was collected 2 months after the end of the study period, and that for this state, data were only collected on claims that were still active at the date of collection. In most cases, medians and means are quite similar. We also present the fraction with censored claims durations, which are around $40 \%$ in CT and MA.

The top panel of Table 5 displays differences in means and quantiles for the observed claim duration distribution. Any impact of the experimental procedures from this table should be associated with the work search component of the experimental procedures. We also present the results of the decomposition of means outlined above. It is clear from Table 5 that the experimental procedures had little effect (if any) in reducing the length of the unemployment

details on that approach of computing standard errors, see Efron and Tibshirani (1993). 
spells. None of the difference in means and quantiles is statistically different from 0 . The decomposition of the difference in means reveals that in $\mathrm{CT}$, most of the difference is explained by the difference in the probability of censoring, while in MA, most of the difference is explained by the difference in the means of censored claims. Regression adjusted results are presented in the bottom panel of Table 5, and they are very similar to the reports in the top half of the table. In sum, the experimental procedures, in particular the work search component, were unsuccessful in reducing the length of unemployment spells.

\section{Pooling the Data}

We present in Table 6 the analysis of the response to the treatment obtained by grouping observations from all the states ${ }^{15}$. We present simple differences in means (or in quantiles) as well as regression adjusted estimates. Each regression controls for observed characteristics ${ }^{16}$ of the claimants as well as state fixed effects. The results are consistent with those presented in Tables 3-5. The only element of the experimental procedures that had a significant impact is apparently the review of eligibility, as some of the treatment effects associated with the qualification rate are statistically significant. Claimants in the treatment groups in the four states are $5 \%$ less likely to qualify for benefits in the first week and $3 \%$ more likely to be disqualified than claimants in the control groups. The responses to the treatment related to benefit received and claim duration are not significant and they are very small in magnitude. The results for CT and MA, where data censoring is not a problem, are similar.

\section{Conclusion}

The results of the randomized trials reported in this study cast doubt on the efficacy of many claims about abusive behavior in the U.S. unemployment insurance system. We found some evidence that, in one of the four states we studied, tighter checks on eligibility may have a small effect on initial benefit payments. However, even in this state, eligibility checks led to little

\footnotetext{
${ }_{14}^{14}$ These dates of measurement are presented in appendix $A$.

${ }^{15}$ The data are pooled without weighting.

${ }^{16}$ The regressions on all four states include controls for age, sex, and race only since annual income is not available for

VA. The regressions for CT and MA only control for age, sex, race and annual income.
} 
or no effect on total benefit payments or the duration of unemployment claims. Most important, we found no evidence that verification of claimant search behavior led to shorter claims or lower total benefit payments.

There are, of course, many potential limitations of these results. First, the experiments were conducted only in four states, and the results might be different elsewhere. Second, the experiments were conducted at a time when the aggregate unemployment rate was considerably higher than it is today, and this might also affect the results. Only further experimentation can demonstrate whether these issues raise serious problems for the generality of the results.

Many social programs now incorporate sanctions on suspected abusive behavior, including the major welfare programs in the U.S. As with other government programs, the effectiveness of sanctions should be subject to a cost-benefit test. The results in this paper indicate that, at least in one program, the enforcement of sanctions is not worth the cost. 


\section{References}

BURGESS, PAUL, L., AND JERRY J. KNIGSTON (1987): An Incentives Approach to Improving the Unemployment Compensation System, W. E. Upjohn Institute for Employment Research.

DeGROOT, MAURICE (1987): Probability and Statistics, Addison-Wesley Publishing Company, Reading, Massachusetts.

EFRON, BRADLEY, AND ROBERT J. TIBSHIRANI (1993): An Introduction to the Bootstrap, Chapman and Hall, New York.

HAM, JOHN, C., AND ROBERT J. LALONDE (1996): "The Effect of Sample Selection and Initial Conditions in Duration Models: Evidence From Experimental Data on Training," Econometrica, $64,175-205$.

HAUSMAN, JERRY, AND DAVID WISE (1985):"Technical Problems in Social Experiment: Cost Versus Ease of Analysis" In Hausman, Jerry, and David Wise, (eds.), Social Experimentation, Chicago: University of Chicago Press for NBER, 187-208.

HECKMAN, JAMES, J. (1992): "Randomization and Social Policy Evaluation," In Manski, C. and Garfinkel, I. (eds.) Evaluating Welfare and Training Programs, Cambridge, Mass: Harvard University Press, 201-230.

HECKMAN, JAMES, J., JEFFREY SMITH, AND NANCY CLEMENTS (1997): "Making the Most Out of Programme Evaluations and Social Experiments: Accounting For Heterogeneity in Programme Impacts," Review of Economic Studies, 64, 487-535.

JENKS, CHRISTOPHER (1992): Rethinking Social Policy, Cambridge, Mass: Harvard University Press.

KINGSTON, JERRY, L., PAUL L. BURGESS, AND ROBERT D. ST-LOUIS (1986): "Unemployment Insurance Overpayments: Evidence and Implications," Industrial and Labor Relations Review, 39, 323-336.

MEYER, BRUCE D. (1995): "Lessons From The U.S. Unemployment Insurance Experiments," Journal Of Economic Literature, vol. XXXIII, 91-131.

MURRAY, CHARLES (1984): Losing Ground, Basic Books Publishers, New York.

WOLF, DOUGLAS, AND DAVID GREENBERG (1986): "The Dynamics of Welfare Fraud: An Econometric Duration Model in Discrete Time," Journal Of Human Resources, vol. XXI, 437-455. 
Figure 1: Typical Processing of Claims in the Treatment and Control Groups in the Field Experiment.

First Visit

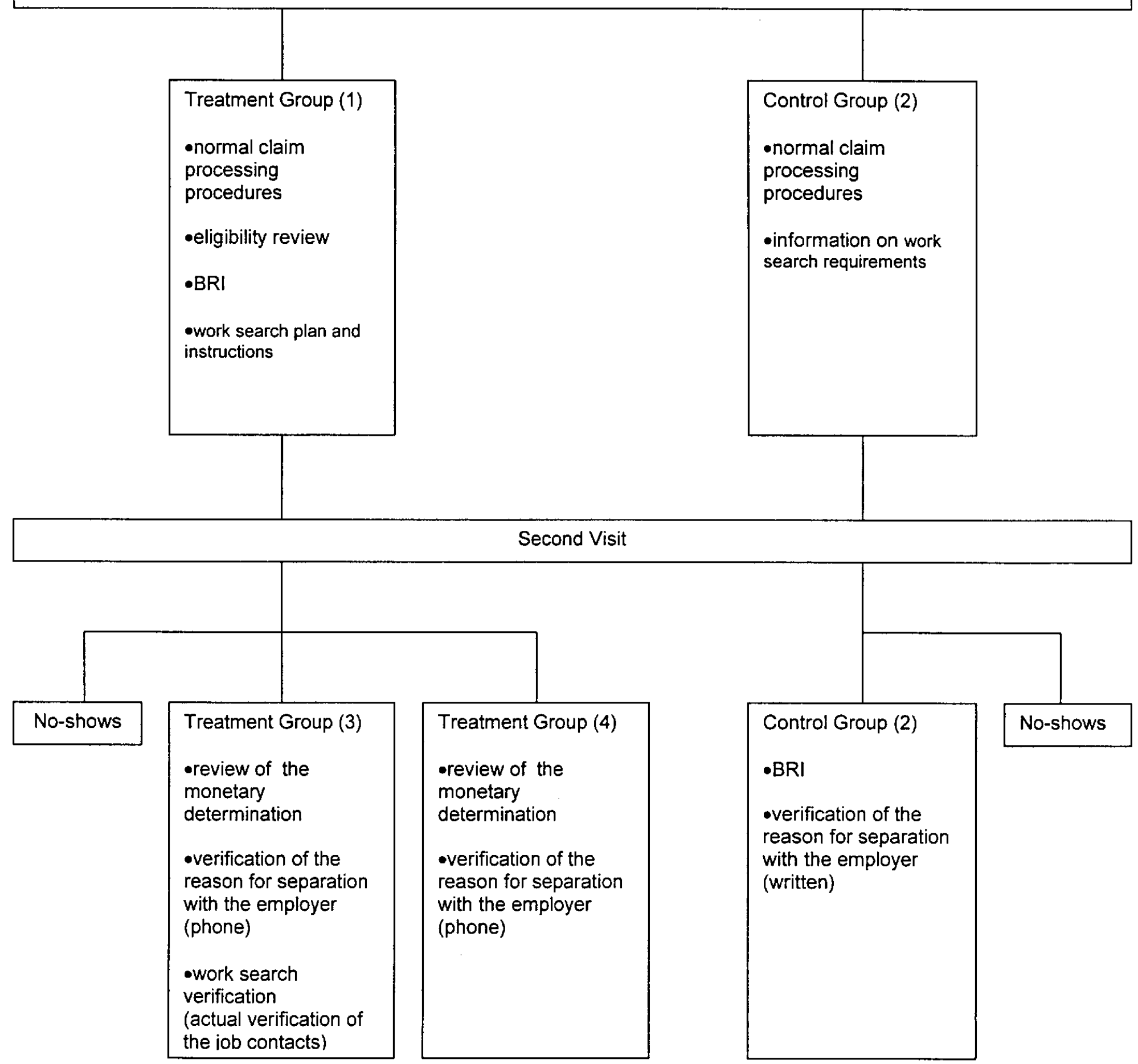




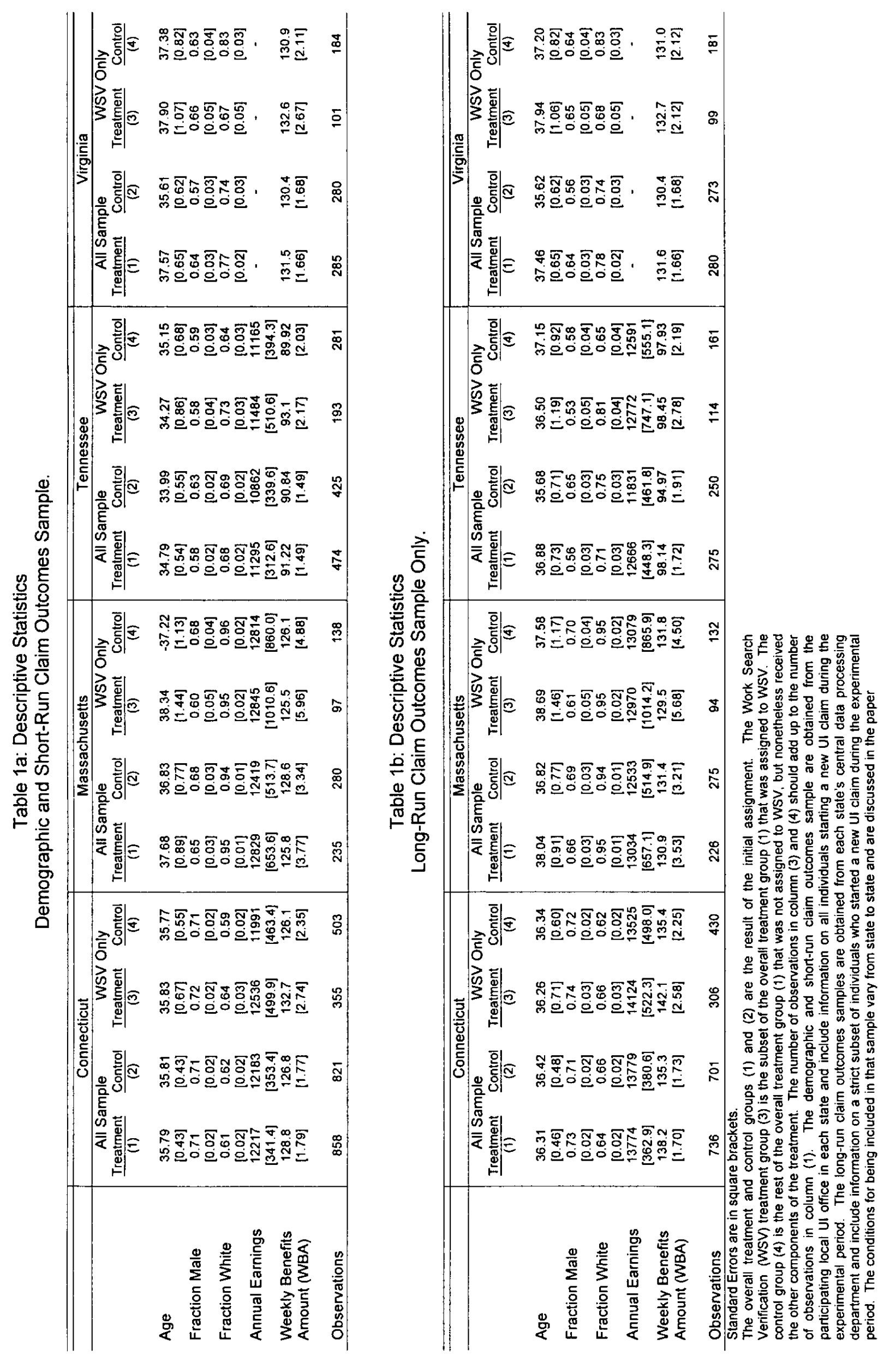




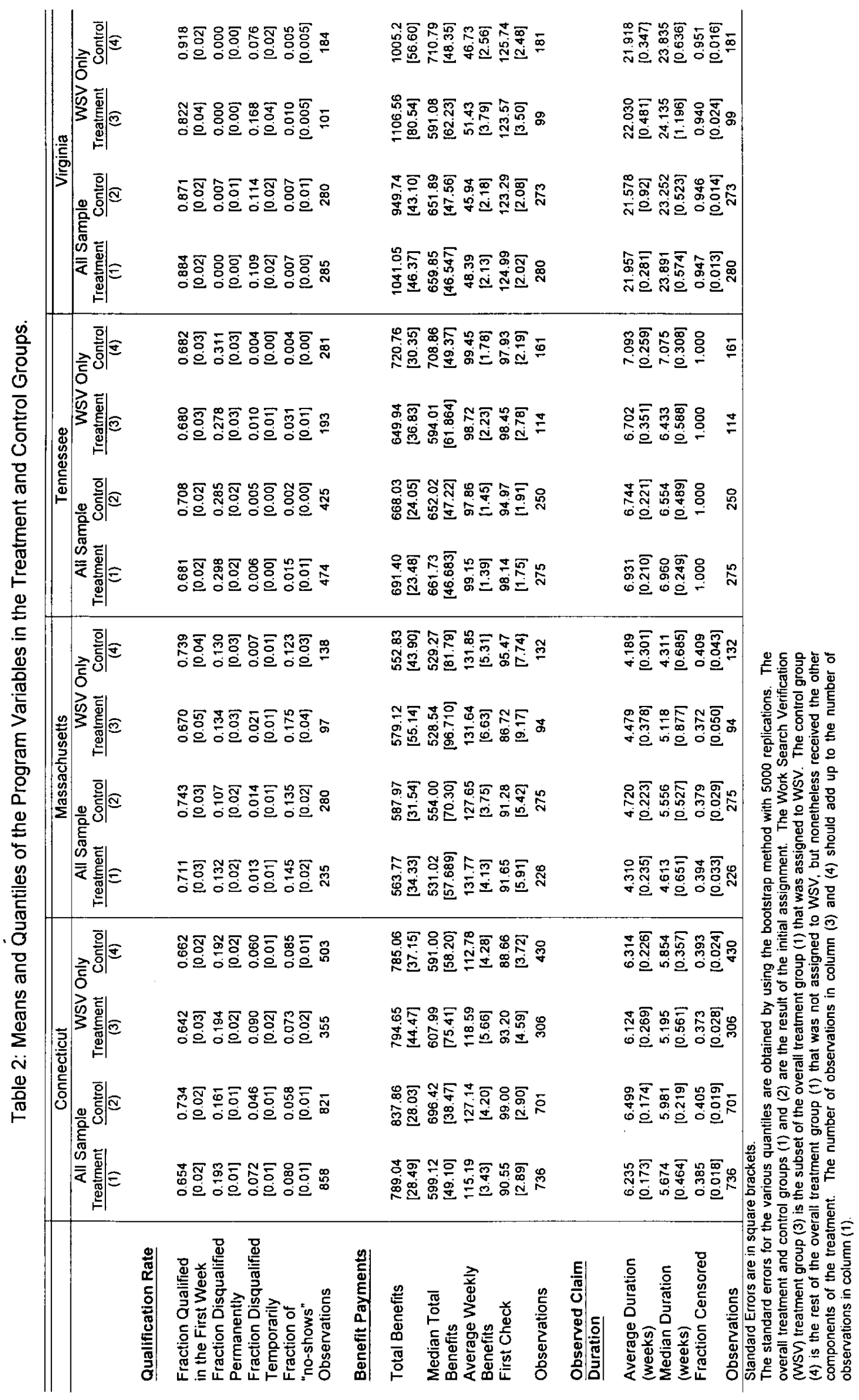




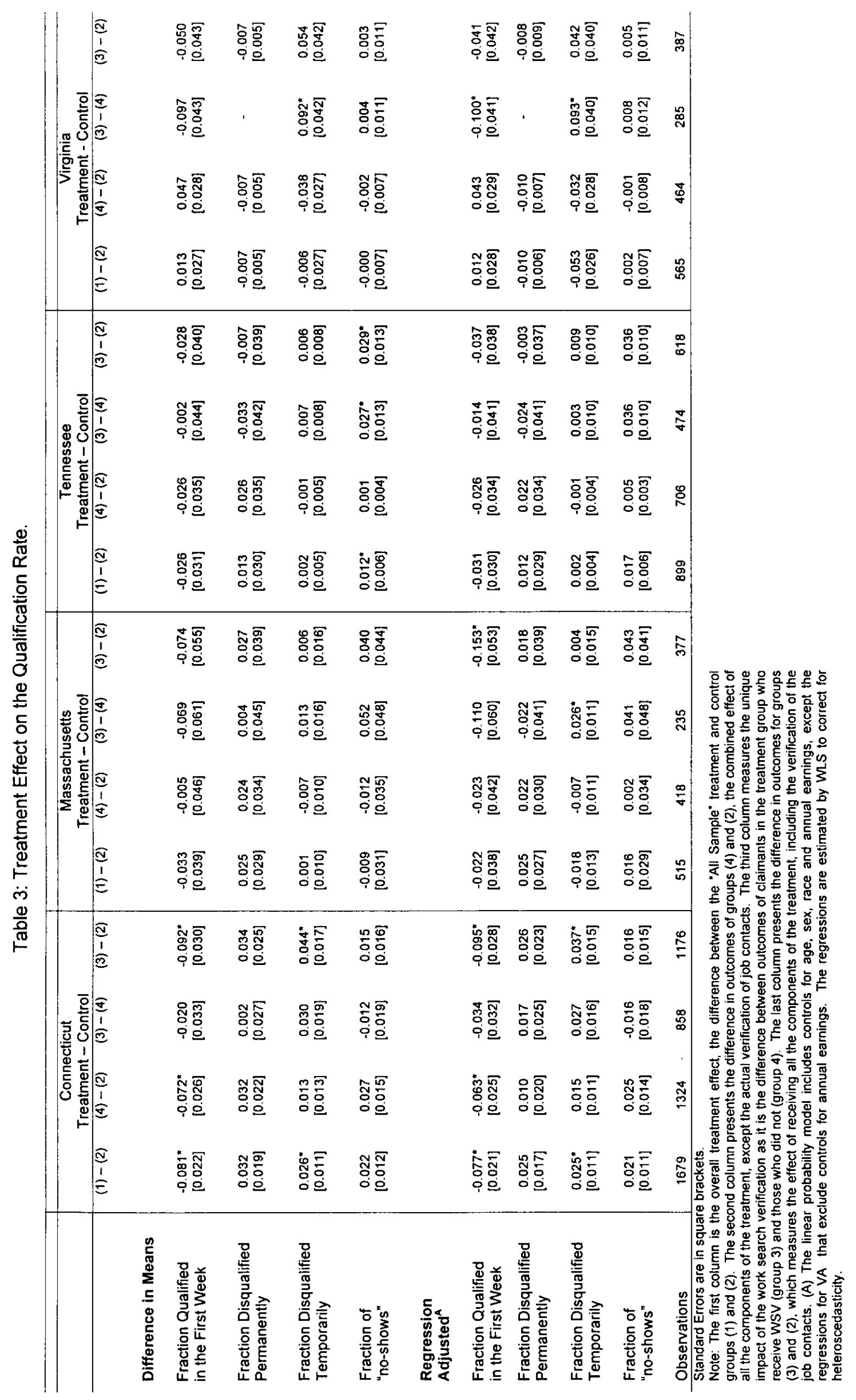




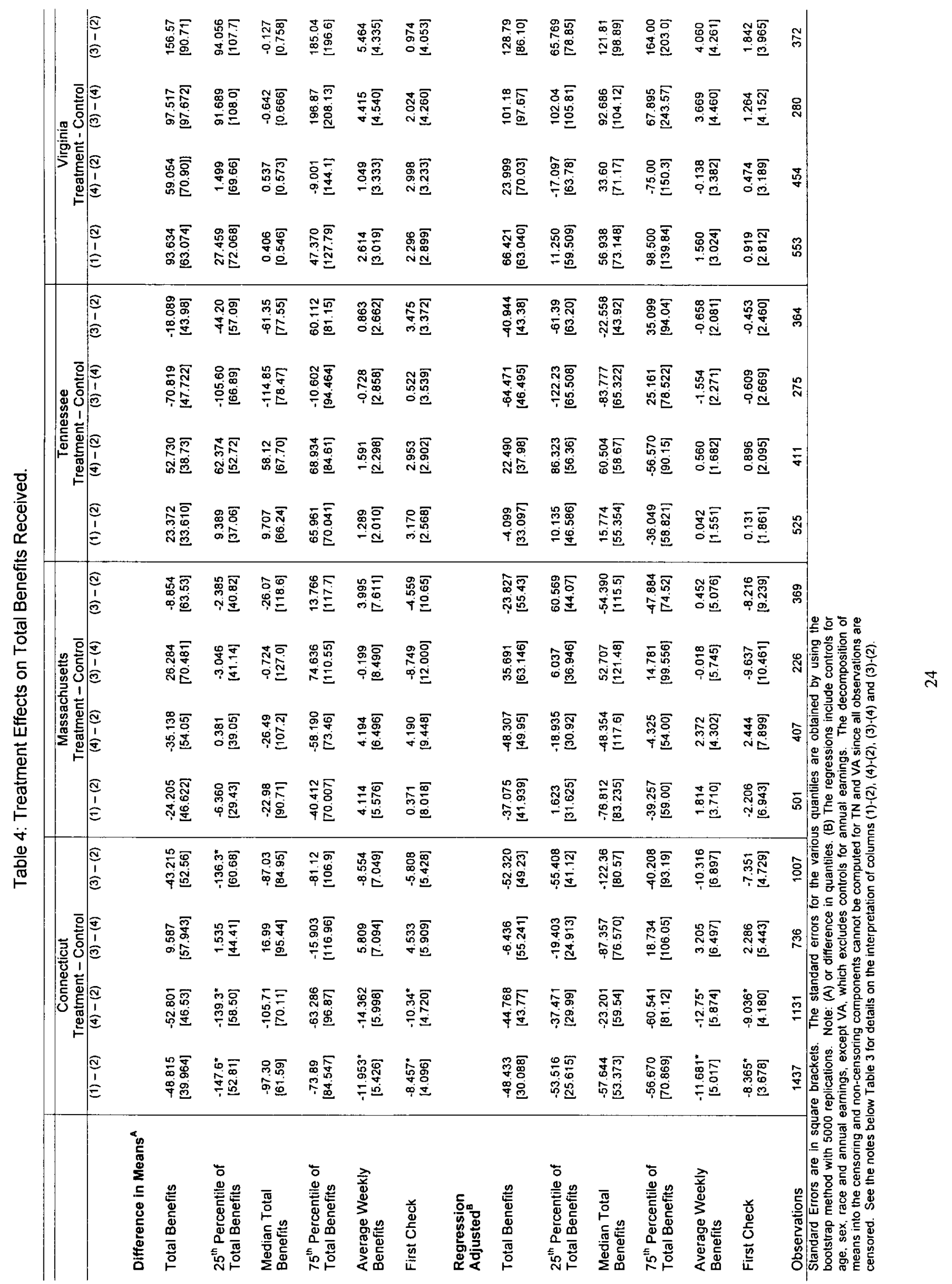




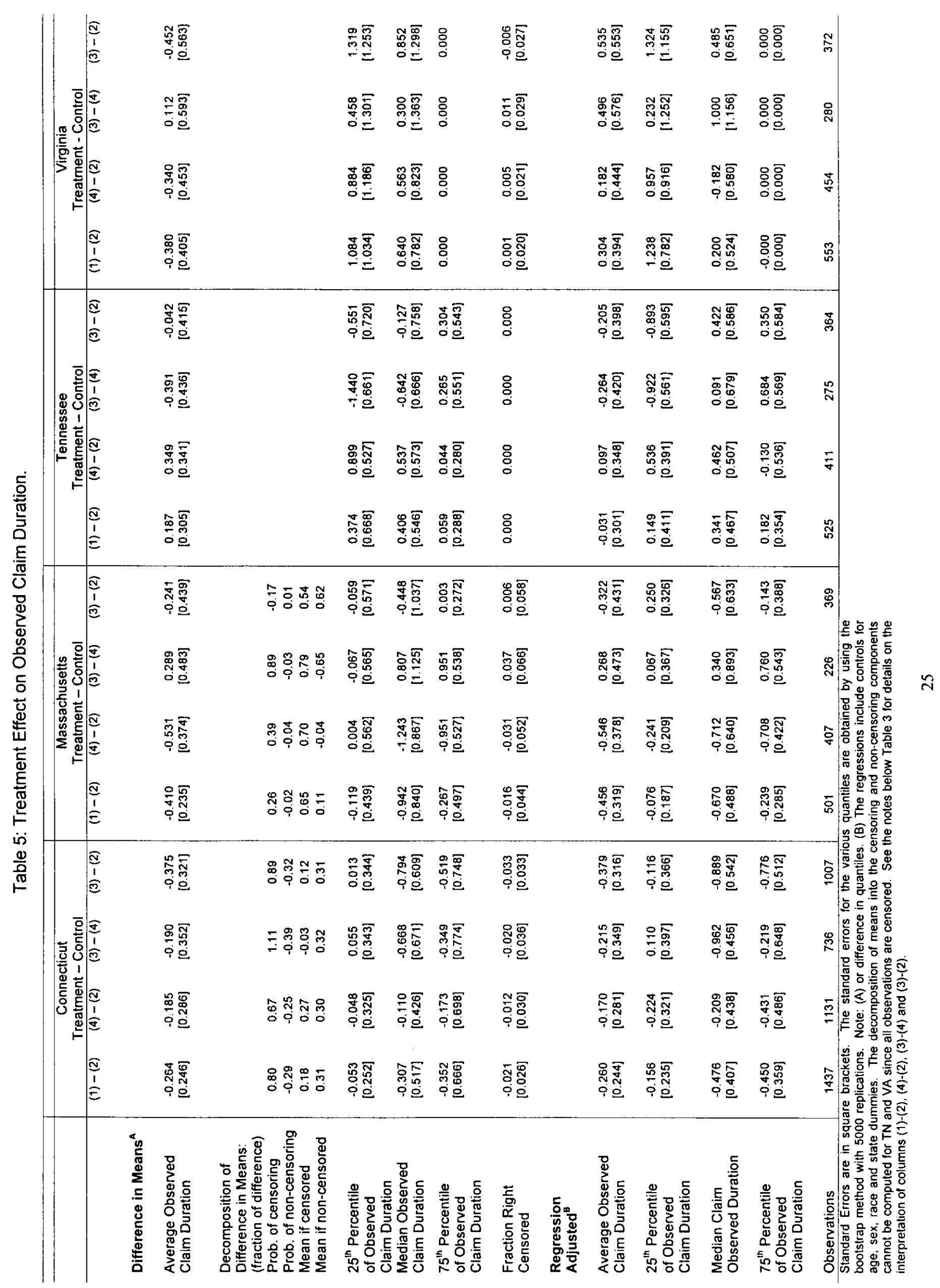




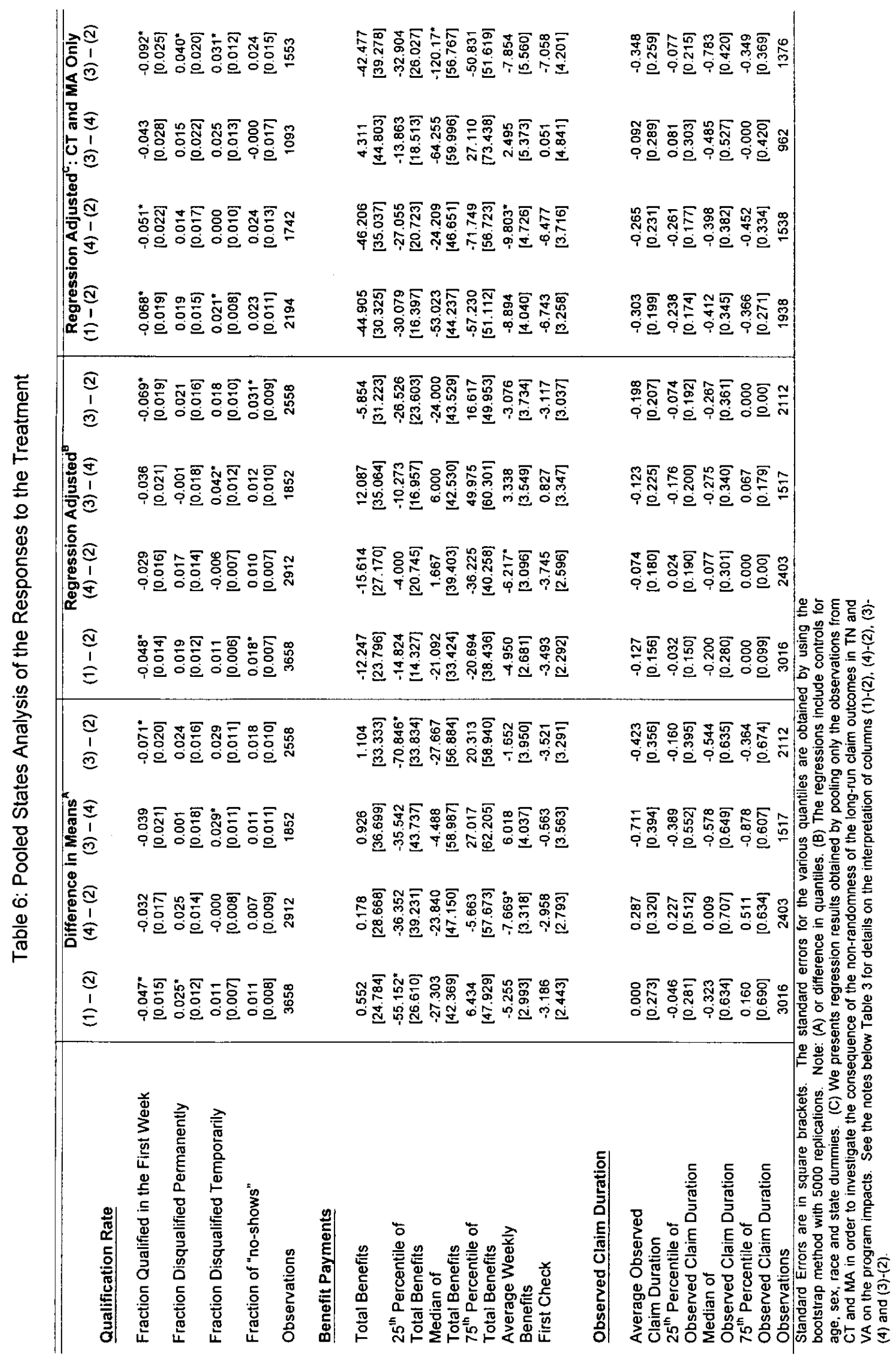


Appendix 


\section{Differential impact of the experimental procedures across states}

There are a number of differences among the four participating states with respect to existing new claim processing procedures, formats and policies. In some states, pre-existing processing procedures already included steps that are under study. Consequently the specific treatment that will be applied in each state will vary. In each of the states it will consist of a combination of some new steps and "front-loading" of some current ones. The major differences across states are summarized in Table 1 in the appendix.

Table A-1: Major Differences in the Treatment Across States.

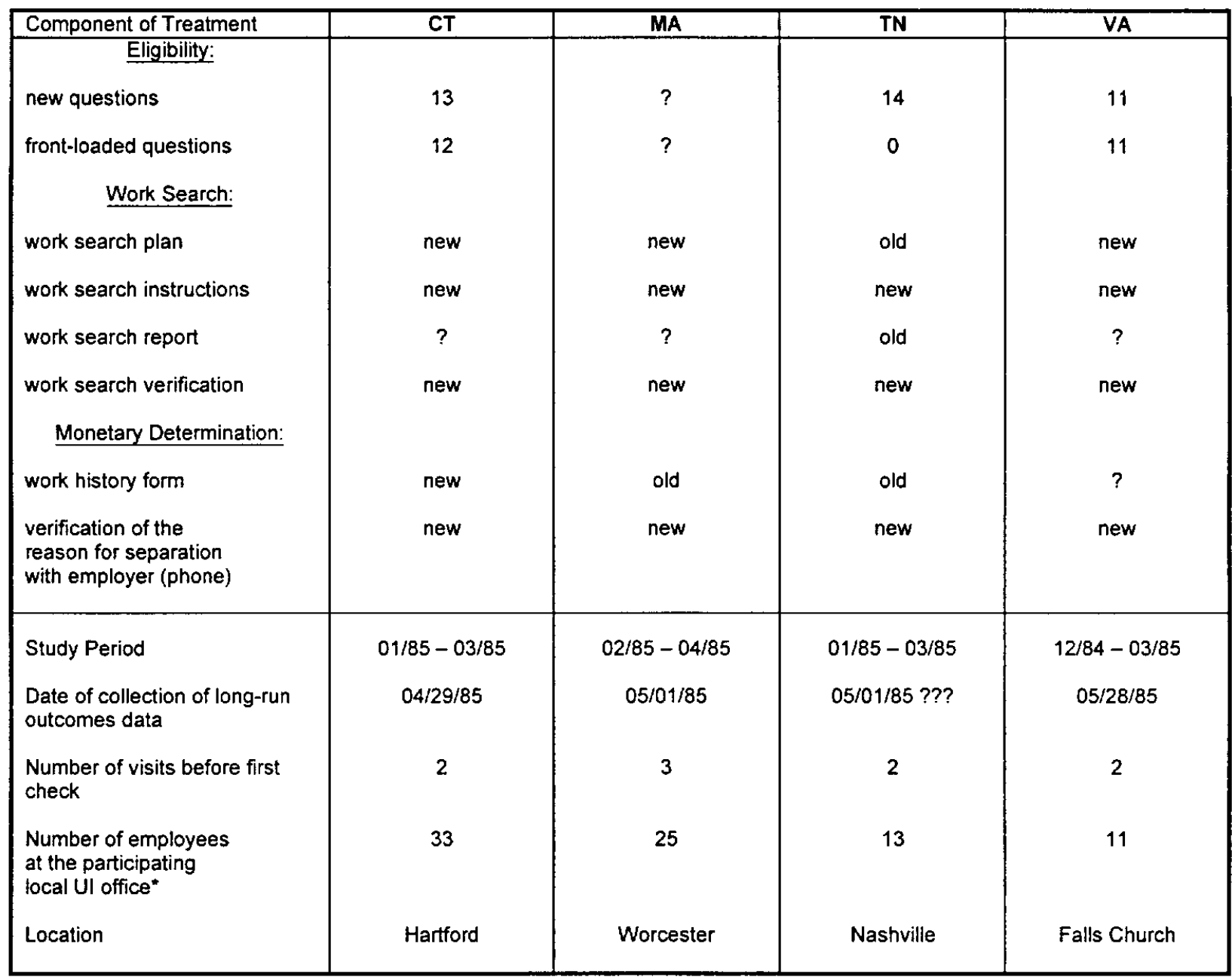

Note: In rows 2 and 3 a NEW means that the element is new to the state processing procedures, a OLD indicates that the state procedure already included a similar step. We denote ambiguities by a "?". The number of employees refers to the employees involved in the experiment. 